\title{
FOUCAULT E GOFFMAN: EM TORNO DE INSTITUIÇÕES E PODERES
}

\author{
FOUCAULT AND GOFFMAN: AROUND INSTITUTIONS AND POWER
}

Heraldo de Cristo Miranda*

\begin{abstract}
RESUMO
O objetivo deste trabalho é propor uma breve reflexão acerca do empreendimento foucaultiano e a tradição do Interacionismo simbólico, em especial, Erving Goffman. Neste último, recolocam-se as questões ligadas à relação do indivíduo e suas instituições. Reabre-se, da mesma forma, a possibilidade de um diálogo com os "enfrentamentos" de Foucault e Goffman quanto à ideia de instituição total, bem como quanto ao tema do poder. Tentar-se-á organizar o percurso desse enfrentamento, eminentemente por meio de três categorias de textos produzidos por Foucault na década de 1970: livros, cursos realizados no Collège de France e algumas palestras, conferências, etc. condensadas nos chamados Dits et Écrits. A questão a ser respondida aqui é: quais as características dessa leitura de Foucault a respeito das ideias de Goffman? Se, por um lado, Goffman se interessa pelo funcionamento de certo tipo de instituição: a instituição total - asilo, escola, prisão; por outro lado, Foucault tenta mostrar e analisar a relação que existe entre um conjunto de técnicas de poder e de formas políticas como o Estado.
\end{abstract}

PALAVRAS-CHAVES: Foucault . Filosofia. Goffman. Poder. Instituição.

\section{ABSTRACT}

This work aims at proposing a brief reflection about Foucauldian enterprise and the symbolic interactionism tradition, in particular, Erving Goffman. On the latter, there are resubmitted issues related to the relationship of the individual and his/her institutions. It is spread again, the possibility of a dialogue with Foucault and Goffman confrontations concerning the idea of total institution, as well as the subject of power. There will be an attempt to organize the course of this confrontation, notably, through three categories of texts produced by Foucault in the 1970s: books, courses held at Collège de France and some lectures, conferences, etc. condensed in the so-called Dits et Écrits. The question to be answered here is: what are the characteristics of this Foucault's interpretation around Goffman's ideas? If, on the one hand, Goffman is interested in the operation of certain type of institution: the total institution asylum, school, prison, on the other hand, Foucault tries to present and analyze the existing connection between a group of power techniques and political forms like the state.

KEYWORDS: Foucault. Philosophy. Goffman. Power. Institution.

\footnotetext{
* Professor do Instituto Federal de Educação, Ciência e Tecnologia do Pará. Graduação em Ciências Sociais, Mestrado em Sociologia e Doutorado em Ciências Sociais pela Universidade Federal do Pará. E-mail: heraldomiranda1@gmail.com.
} 


\section{INTRODUÇÃO}

Em 19 de abril de 1983, em Berkeley, Estados Unidos, Michel Foucault faz uma das últimas referências a Erving Goffman, em um debate realizado no departamento de História da Universidade da Califórnia. Esse evento fez parte de uma série de sessões ocorridas também nos departamentos de Filosofia e Estudos franceses, durante a primavera daquele ano, naquela universidade. Entre os vários interlocutores presentes aos debates estavam intercaladamente autores como Leo Lowenthal, Charles Taylor, Herbert Dreyfus e Paul Rabinow ${ }^{1}$. Dois aspectos importantes, penso. Por um lado, a presença de Herbert Dreyfus e Paul Rabinow ratifica os seus importantes trabalhos de recepção das ideias de Foucault nos Estados Unidos. Por outro lado, a referência acima é um indício de que há uma leitura de Foucault acerca de Goffman que se estende por anos, desde seus estudos realizados sobre as prisões no início da década de 1970. O objetivo, portanto, aqui é pensar: quais as características dessa leitura que Foucault faz das ideias de Goffman?

\section{GOFFMAN E A ANÁLISE DAS INSTITUIÇÕES}

No fim dos anos 1950, Goffman torna-se professor de Antropologia e Sociologia na Universidade de Berkeley, na Califórnia - Universidade que se habituaria a receber Foucault durante os anos 1970 e início da década de 1980. É possível inserir aquele entre os autores do chamado interacionismo simbólico, abordagem da sociologia norte-americana, saída da Escola de Chicago. Durante os anos 1960 e 1970 ocorre um intenso interesse, nos Estados Unidos, pelas pesquisas ligadas ao interacionismo simbólico; uma de suas principais características é a tentativa de compreender a organização das interações sociais em contextos do cotidiano, em especial os ambientes institucionais, como asilos, hospitais etc. $\mathrm{O}$ interacionismo recoloca as questões ligadas à relação do indivíduo e seu meio. Uma das questões cruciais no empreendimento de análise de Goffman é sem dúvida o exame das situações de interação, a fim de compreender a maneira pela qual se constitui ou mesmo funciona certa ordem social. Os dilemas produzidos pelas questões da Ordem e da Interação

\footnotetext{
${ }^{1}$ O antropólogo Paul Rabinow e o filósofo Hubert Dreyfus são professores na Universidade da Califórnia, em Berkeley (DREYFUS; RABINOW, 1984). Acerca da recepção norte-americana do pensamento de Foucault é digno de nota o trabalho de François Cusset (2003); assim como o livro de David Halperin (2000) e o artigo de Marcus Wohlsen (2005). E para uma leitura específica da recepção do pensamento foucaultiano na antropologia norte-americana, vide Miranda (2016).
} 
Social estarão presentes no pensamento de Goffman desde seus primeiros trabalhos ${ }^{2}$. Goffman trata, na verdade, de uma ordem da interação, posto que da mesma forma que uma "ordem jurídica", por exemplo, a interação também traz consigo uma ordem que submete a seus partícipes um conjunto infindável de regras e obrigações. Como muito bem destacaram Cefai e Gardella (2012), um questionamento central nas análises de Goffman é: como as ações podem engendrar uma ordem social? Para Goffman, as instituições preencheriam as funções de integração e de regulação por meio das quais os indivíduos interiorizariam uma ordem social, na qual a interação traria consigo suas leis próprias. Subjaz, portanto, o tema do reconhecimento e seus ritos de interação.

Entretanto, é claro também que um dos temas mais abordados em Goffman frente, em especial, a sua recepção brasileira é aquele da instituição total.

Toda instituição conquista parte do tempo e do interesse de seus participantes e lhes dá algo de um mundo; em resumo, toda instituição tem tendências de fechamento. Quando resenhamos as diferentes instituições de nossa sociedade ocidental, verificamos que algumas são muito mais fechadas do que outras. Seu fechamento social com o mundo externo e por proibições à saída que muitas vezes estão incluídas no esquema físico - por exemplo, portas fechadas, paredes altas, arame farpado, fossos, água, florestas ou pântanos. A tais estabelecimentos dou o nome de instituições totais (GOFFMAN, 2008, p.16).

No prefácio de seu A representação do eu na vida cotidiana, o autor já reivindica um tipo de analise acerca do fenômeno institucional: "Este trabalho serve como uma espécie de manual que descreve detalhadamente uma perspectiva sociológica a partir da qual é possível estudar a vida social, principalmente aquela que é organizada dentro dos limites físicos de um prédio ou de um fabrica" (GOFFMAN, 1983, p. 9). Portanto, destaco dois aspectos. Por um lado, a reivindicação de uma separação entre um mundo da sociedade e um mundo da instituição. Existiria uma clara distinção entre ações realizadas naquela circunscrição das instituições totais e aquelas efetuadas na sociedade, ou seja, as situações de interação interna às instituições diferenciar-se-iam daquelas situações de interação que a sociedade em geral promoveria. Por outro, subjaz uma reflexão pela qual o poder negativiza-se, traz em sua fisionomia o centralismo da autoridade institucional que monopolizaria as ações, que teria quase que exclusividade no exercício dos procedimentos repressivos, um poder mais visto pelas leis gerais de autoridade que pelos detalhes das relações. Dirá Goffman:

\footnotetext{
${ }^{2}$ A obra de Goffman analisada no Brasil, via de regra, restringe-se principalmente a três livros: Goffman (1983); (2001); (1978). Mais recentemente, Goffman (2011).
} 
uma disposição básica da sociedade moderna é que o individuo tende a dormir, brincar e trabalhar em diferentes lugares, com diferentes coparticipantes, sob diferentes autoridades e sem um plano racional geral. $\mathrm{O}$ aspecto central das instituições totais pode ser descrito com a ruptura das barreiras que comumente separam essas três esferas da vida [...]. Todos os aspectos da vida são realizados no mesmo local e sob uma única autoridade. (GOFFMAN, 2008, p.17).

Portanto, o poder articula-se à ideia de um controle exercido pela organização, um poder que emana de cima, que se impõe soberanamente sobre os partícipes da interação, ou seja, "o controle de muitas necessidades pela organização burocrática de grupos completos de pessoas - seja ou não uma necessidade ou meio eficiente de organização social nas circunstâncias - é o fato básico das instituições totais" (GOFFMAN, 2008, p.18). Além disso, circunscreve-se uma clara cisão entre o lugar do "fora" e o do enclausuramento, o mundo da sociedade e o mundo da instituição, ou dito de outra maneira,

se a estada do internado é muito longa, pode ocorrer, caso ele volte para o mundo exterior, o que já foi denominado desculturamento [...]. Nesse sentido, as instituições totais realmente não procuram uma vitória cultural. Criam e mantêm um tipo especifico de tensão entre o mundo doméstico e o mundo institucional, e usam essa tensão persistente como força estratégica no controle de homens. (GOFFMAN, 2008, p.23).

\section{O PODER E SUA MICROFÍSICA}

A noção de poder na obra de Foucault espalha-se entre livros, artigos, conferências, cursos, etc. Um caminho repleto de deslocamentos. Encontraremos referências ao poder e seus desdobramentos nas três séries de textos, pelas quais se podem organizar os trabalhos de Foucault, quais sejam, os livros que discutem a questão, os textos de conferências, palestras, entrevistas, etc., organizados em seus Dits et Écrits em 1994, ou mesmo aquelas referências ao poder, presentes nos cursos realizados por Foucault no Collège de France.

Em Le Pouvoir Psychiatrique, curso de 1973-1974, no Collège de France, Foucault situa alguns deslocamentos em relação ao trabalho desenvolvido em Histoire de la Folie. “Gostaria de tentar ver se é possível fazer uma análise radicalmente diferente [...]. Colocar como ponto de partida a análise não mais nesse espaço de núcleo representativo que levaria necessariamente a uma história das mentalidades, do pensamento, mas um dispositivo de poder" (FOUCAULT, 2003, p. 14, tradução nossa). Sair-se-ia de uma análise das representações para uma analítica do poder; deixar-se-ia uma discussão em torno da violência para alcançar uma microfísica do poder; afastar-se-ia do imperativo do corpus institucional 
para aproximar-se de uma reflexão sobre os dispositivos de poder. Foucault entende aqui dispositivo como um conjunto heterogêneo de discursos, instituições, leis, medidas administrativas, enunciados científicos, proposições filosóficas, morais, técnicas, estratégias e formas de assujeitamento, e a isso, forja-se uma ideia acerca do poder. Destaco a noção de dispositivo, pois aponta um deslocamento de Foucault em relação aos textos da década de 1960, como Les Mots et les Choses e L'Archeologie du Savoir, nos quais a ideia de épistémè surge fundamentalmente como um tipo de dispositivo discursivo, enquanto que essa noção de dispositivo usado na década de 1970 alarga-se em direção às instituições, às práticas, ao não discursivo, etc. Em um dado sentido, paulatinamente, Foucault substitui a épistémè por dispositivo. Como ficará claro, em entrevista realizada em 1977, sobre o lançamento do primeiro volume da Histoire de Sexualité:

\footnotetext{
É isso o dispositivo: estratégias de relações de forças suportando tipos de saber e, ao mesmo tempo, suportados por eles. Em Les Mots e les Choses, tentando fazer uma história da épistémè, eu permanecia em um impasse. Agora, o que gostaria de fazer, é tentar mostrar que o que chamo de dispositivo é um caso muito mais geral que o de épistémè. Ou antes, que a épistémè é um dispositivo especificamente discursivo, diferentemente do dispositivo que é discursivo e não discursivo, sendo seus elementos muito mais heterogêneos. (FOUCAULT, 2001, p. 300, tradução nossa).
}

Ora, é em meio a esses deslocamentos que a noção de poder se constrói. É assim que Foucault, em Le Pouvoir Psychiatrique, na aula do dia 14 de novembro de 1973, distingue entre, de um lado, uma macrofísica da soberania, monopolizada pela figura central do rei, e de outro, uma microfísica do poder, ou o amadurecimento da ideia de um poder disciplinar que se manifesta em todos os lugares. É nesse cenário do poder disciplinar e das instituições totais que se desenvolverá o debate entre Foucault e Erving Goffman, por exemplo.

No curso intitulado Les Anormaux, de 1974-1975, no qual trabalha como na história do Ocidente, deu-se a constituição da concepção de anormalidade, Foucault destaca, a meu ver, três aspectos importantes quanto ao debate acerca do poder. Primeiramente, na aula do dia 8 de janeiro de 1975, mostra-se que um dos traços essenciais das grandes burocracias ocidentais desde o século XIX foi a máquina administrativa e seus efeitos de poder, com seus funcionamentos nulos, medíocres; a burocracia moderna tendo como elemento inerente uma espécie de grotesco administrativo. "O que eu digo da burocracia moderna, poderia se dizer mesmo de outras formas de mecânicas de poder." (FOUCAULT, 1999, p.13, tradução nossa). Aqui, outro olhar sobre a maneira pela qual se pensa o poder: afastando-se de uma tradição

\footnotetext{
${ }^{3}$ Sobre um histórico da noção de épistémè, ver Ravel (2009, p. 41).
} 
contratualista, por exemplo, de Hobbes, que centraliza o poder no soberano e aproximando-se de uma reflexão sobre as formas de uma mecânica do poder, o qual se caracteriza pela dispersão de uma autoridade. Segundo, na mesma aula referida, Foucault fala de uma mudança na maneira como o indivíduo delinquente será tratado na sociedade moderna; deixando de ser tomado a partir do parâmetro do juridicamente responsável, para ser visto como o elemento partícipe de um universo de técnicas de normalização. "Essa emergência do poder de normalização, a maneira que se formou, a maneira que se instalou, sem que jamais tomasse apoio sobre uma única instituição, mas pelo jogo que chegou a estabelecer entre as diferentes instituições, estendeu sua soberania em nossa sociedade" (FOUCAULT, 1999, p. 24, tradução nossa). Por último, já na aula do dia 15 de janeiro de 1975, mostra como a idade clássica criou inúmeras técnicas de poder, elaborou aparelhos administrativos, procedimentos de maximização da produção; trata-se de uma maneira de pensar, na qual o poder é menos um simples exercício de exclusão, de proibição, que se caracterizaria por um tipo de violência contínua que uns exerceriam sobre os outros, mas antes, seria o poder, ligado a tecnologias positivas do poder, ou seja, "a ideia de que o poder - no lugar de permitir a circulação, os revezamentos, as combinações múltiplas dos elementos - tem essencialmente por função proibir, impedir, isolar, parece-me uma concepção de poder que se refere a um modelo historicamente ultrapassado" (FOUCAULT, 1999, p. 47, tradução nossa).

Essas reflexões acerca do poder ocorrem, por exemplo, concomitantemente em Surveiller et Punir. Nele, expõe-se o surgimento de uma sociedade estruturada ou constituída por um novo tipo de poder-saber, no qual a importância está menos centralizada na verticalidade do poder soberano, e mais na difusão generalizada das relações disciplinares. As técnicas de adestramento que existiriam já nas escolas, nos quartéis, nos hospitais etc., desenvolver-se-iam e se sistematizariam na sociedade das luzes, no fim do século XVIII. Com a penitenciária, essa nova forma de punir verá o florescimento de técnicas de adestramento que agirão sobre os corpos e as almas. Foucault recorrerá ao filósofo utilitarista inglês Jeremy Bentham (1748-1832), pois é sob a forma panóptica, pensada por Bentham ${ }^{4}$, que o fenômeno da observação passa por um processo de mudança, cujo traço fundamental é também o adestramento do indivíduo delinquente. Para Foucault, o panóptico é um modelo de prisão, no qual a relação de poder torna-se total, ou seja, um modelo cujo funcionamento será a figura emblemática da sociedade disciplinar, definindo as relações de poder do indivíduo em sua relação com a vida cotidiana e com a cultura.

\footnotetext{
${ }^{4}$ Para um aprofundamento da relação entre Foucault e Bentham, ver Laval (2011).
} 
Talvez o grande questionamento de Surveiller et Punir seja como aquele modelo coercitivo, corporal, solitário e secreto do poder exercido pela punição foi substituído pelo modelo representativo, público, coletivo. A análise de Foucault se desenrolará em torno do suplício, da punição e da disciplina das prisões.

Segundo Foucault, no período do Antigo Regime a maneira mais comum de sanção às transgressões legais cometidas pelos indivíduos era a punição dos corpos por meio dos suplícios, isto é, uma técnica, uma pena que carrega consigo três características fundamentais: 1. Deve produzir certa quantidade de sofrimento; 2. Pertence ao campo de uma economia jurídica da dor, da agonia, etc. 3. Ele faz parte de um ritual. É o elemento de uma liturgia punitiva, que deve ser marcante e repleta de torturas, cicatrizes que marcarão e circunscreverão os corpos com um terreno sobre o qual o poder age. O famoso suplício de Damien, ocorrido em 1757 na França e que inicia o livro, será, para Foucault, a expressão maior daquela época quanto a uma genealogia da pena. $\mathrm{O}$ criminoso não será gerido pelas determinações das leis, mas por uma lei que emana diretamente do soberano. A punição aqui será o emblema de uma vingança do soberano; uma vingança que se exprime nos corpos dos supliciados. Não se trata de justiça, mas sim um castigo vingativo exercido pelo rei sobre aquele que o desafiou. O rei, dirá Foucault, gostaria de "mostrar que o poder soberano que revela o direito de punir não pode em nenhum caso pertencer à multidão. Frente à justiça do soberano, todas as vozes devem se calar" (FOUCAULT, 2010, p. 43, tradução nossa). O suplício é uma cerimônia na qual os corpos são o lugar da expiação. É nos corpos que é reproduzido o horror, a barbárie do crime.

No fim do século XVIII, o suplício torna-se uma prática questionável. Começa a ser visto pelo parâmetro da intolerância. Não era incomum o suplício ser, segundo Foucault, o estopim de insurreições, de revoltas, até mesmo por conta da dimensão espetacular e comovente dos suplícios públicos realizados. A ideia predominante agora seria a de punir de uma maneira diferente. Desmorona-se o afrontamento físico que o soberano realizava frente ao condenado. Há uma "nova economia do poder de punir", que está associada diretamente a um crescimento demográfico e econômico daquela nascente sociedade capitalista. As infrações não se relacionam mais ao poder soberano do rei, mas ao corpo social como um todo. Foucault demarca um deslocamento do direito de punição: não se justifica mais sob a vingança do soberano, mas sob a defesa da sociedade. O empreendimento punitivo está ligado ao medo da desordem social que o crime pode provocar. "Um poder de punir que alcançava toda rede social, agia em cada um de seus pontos, e acabava por não ser mais percebido como 
um poder de alguns sobre outros, mas como reação imediata de todos em relação a cada um." (FOUCAULT, 2010, p. 154, tradução nossa).

Em síntese, o estudo sobre as prisões realizado por Foucault não tem o objetivo de saber se as prisões são corretas ou não, mas sim de entender esses dispositivos de normalização e todas as consequências desse tipo de poder que se exerce agora. Esse empreendimento reflexivo acerca do poder presente em Surveiller et Punir não esta distante das reflexões realizadas por Foucault, por exemplo, nos cursos do Collège de France, à época. Os respingos da pesquisa realizada por Foucault para Surveiller et Punir podem ser lidos no curso de 1976, Il faut défendre la société, pois

\footnotetext{
antes de orientar a pesquisa sobre poder do lado do edifício jurídico da soberania, do lado dos aparelhos de Estado, do lado das ideologias que os acompanham, eu acredito que é preciso orientar a análise do poder do lado da dominação (e não da soberania), do lado das operações materiais, do lado das formas de assujeitamento, do lado das conexões e utilizações dos sistemas locais desse assujeitamento e do lado, enfim, dos dispositivos de saber. (FOUCAULT, 1997, p. 30, tradução nossa).
}

A passagem, presente em Histoire de la Sexualité I - la volonté de savoir, por meio da qual Foucault versará acerca da constituição de um tipo de saber sobre o sexo que coloque o debate em termos de uma mecânica do poder e não de um simples e involuntário processo de repressão, talvez possa ratificar os principais traços dessa reflexão sobre o poder: "o poder não é uma instituição, e não uma estrutura, não é uma certa força com a qual alguns seriam dotados: é o nome que se empresta a uma situação estratégica complexa em uma determinada sociedade" (FOUCAULT, 1976, p. 123, tradução nossa).

\section{O GOFFMAN DE FOUCAULT}

“O poder não é uma instituição". Eis a assertiva que, penso, será um traço crucial nas distinções entre o debate costurado por Goffman e as reflexões realizadas por Foucault. Apesar de algumas tentativas de aproximação entre ambos, por conta do fenômeno asilar ou mesmo por meio da ideia de uma sociedade moderna que se caracterizaria pelos espaços dos enclausuramentos, jamais Foucault pretendeu realizar uma espécie de história das prisões ou dos asilos, ou mesmo um impulso em direção a uma análise das prisões enquanto uma instituição total. A distância entre ele e o autor de Manicômios, prisões e conventos (1961/2008) é singularmente significativa. Em entrevista com M. Dillon, em 1979, Foucault, ao responder sobre os autores que também se preocupam com o problema da manipulação do 
indivíduo pelo Estado e por outras instituições nos Estados Unidos, determina com clareza o seu distanciamento em relação à Goffman:

\begin{abstract}
Os problemas que trato em meus livros não são novos. Eu não os inventei. Uma coisa me impressionou nas resenhas que foram feitas de meus livros nos Estados Unidos, em particular no que se escreveu sobre o livro que consagrei às prisões. Dizse que eu tentava fazer a mesma coisa que Erving Goffman em sua obra sobre os asilos [...]. Não procuro fazer a mesma coisa que Goffman. Ele se interessa pelo funcionamento de um certo tipo de instituição: a instituição total - asilo, escola, prisão. De minha parte, tento mostrar e analisar a relação que existe entre um conjunto de técnicas de poder e de formas políticas como o Estado. (FOUCAULT, 2001, p. 804, tradução nossa).
\end{abstract}

É importante ressaltar que a criação, em 1970, realizada por Foucault, Daniel Defert, Jean-Marie Domenach e Pierre Vidal-Naquet, do GIP - Grupo de informação sobre as Prisões, não apenas contribui com a tarefa de informar sobre a vida cotidiana nas prisões e sua relação com os intelectuais, médicos, magistrados etc., assim como acena para a importância do referido grupo na negação teórica das analises de Goffman no seio dos debates da época, em torno das prisões. Esse distanciamento entre Goffman e Foucault fora apontado no curso Théories et Institutions pénales, 1970-1971, no Collège de France, no qual Foucault tenta recolocar a análise do sistema penal (teorias, instituições e práticas penais) no contexto de sistemas de repressão, ou seja, uma leitura do nascimento da justiça enquanto aparelho repressivo do Estado. A revolta de Nu-pieds, ocorrida em 1639, na França, será a epígrafe histórica para sua reflexão. As análises de Foucault vão em direção ao contexto político francês da época, por exemplo, do tema da repressão, como indica as querelas, em junho de 1970, a respeito da votação da chamada loi anti-casseur, ou seja, uma lei que reprimisse os "vândalos", "baderneiros", "arruaceiros".

Os questionamentos sobre as formas de delinquência, a crítica da função do enclausuramento na sociedade contemporânea, margearão as preocupações de Foucault em torno da dimensão do poder, diferentemente de Althusser, centrado na dimensão do Estado e seus aparelhos. Foucault ratifica as instituições da justiça enquanto um lugar dos enjeux de poder. A justiça estaria no cerne da analítica do poder, isto é, no coração das práticas de justiça. As relações de poder se articulariam de um lado com as relações econômicas e por outro com as formações de saber. Destarte, o problema não é o Estado, seus aparelhos, suas instituições, porém as relações de poder colocadas em ação.

Com esse direcionamento rumo às relações de poder, afastando-se do vocabulário marxista e de uma negativação do poder, é possível encontrar, ao mesmo tempo, um 
distanciamento e uma crítica a Goffman e sua ideia de Instituição total. Torna-se evidente tal crítica quando Foucault organiza os princípios do curso de 1970-1971 no Collège de France:

\begin{abstract}
Substituindo a análise da penalidade nos sistemas de repressão, dá-se a possibilidade de não colocar o problema em termos de moral (bem/mal), em termos sociológicos (desvio/integração), em termos psicológicos (delinquência). Ou antes, é a partir da análise dos sistemas de repressão que se vê como historicamente aparecem ou se reformulam esses temas ou essas noções. (FOUCAULT, 2015, p. 4, tradução nossa).
\end{abstract}

Não tenho dúvida que o interlocutor de Foucault, aqui, é Goffman e sua tradição. Desvio/integração, bem/mal, delinquência/normalidade são dualidades que habitam aquela reivindicação por uma fronteira rígida entre um mundo da sociedade e um mundo da instituição, a existência de uma distinção entre ações realizadas naquela circunscrição das instituições totais e aquelas efetuadas na sociedade, tão fortemente marcantes nos textos de Goffman. No curso do Collège de France 1972-1973, intitulado La Société Punitive, aquela "interlocução" entre Foucault e Goffman recebe traços bem mais evidentes. Nesse curso, Foucault abordará aquilo que será desenvolvido nos estudos futuros, como em Surveiller et Punir, qual seja, a particularidade jurídica e social da forma-prisão.

Esta forma-prisão é muito mais que uma forma arquitetural, é uma forma social. No limite, especulando muito, poderia dizer que se a cidade grega inventou um certo espaço social que é aquele da ágora e que foi a condição de possibilidade institucional do logos, a forma de estrela, do poder de vigilância, dá lugar a uma forma de saber de um tipo novo. Tal foi o ponto de minha proposta: a prisão como forma social, isto é, como forma segundo a qual o poder se exerce no interior de uma sociedade. (FOUCAULT, 2013, p. 230, tradução nossa).

Diferentemente de Goffman, a prisão está para além da prisão. Foucault coloca a questão em termos de processos de assujeitamento, dispositivos de poder, mecanismos de normatização que estão, ao mesmo tempo, dentro e fora das instituições. No mesmo curso do Collège de France 1972-1973, Foucault faz uma importante referência a Lévi-Strauss. Na última parte do livro Tristes Tropiques (1955), intitulada Le Retour, Lévi-Strauss aborda como as sociedades em seus diferentes modos comportam as normas e os seus indivíduos perigosos. Dirá ele:

Nenhuma sociedade é perfeita. Por natureza, todas comportam uma impureza incompatível com as normas que proclamam [...]. Penso em nossos costumes judiciários e penitenciários. Ao estudá-los de fora, estar-se-ia tentado a opor dois tipos de sociedades: aquelas que praticam a antropofagia, ou seja, veem na absorção de certos indivíduos detentores de forças perigosas o único meio de neutralizá-las, ou mesmo de colocá-las a seu proveito; e aquelas que, como a nossa, adotam o que 
se poderia chamar de antropemia (do grego emein, vomitar). (LEVI-STRAUSS, 2011, p. 464).

A reflexão acerca da punição é o motivo da referência de Foucault a Lévi-Strauss, como muito bem nos lembra Ernani Chaves, "a questão de Foucault é a de saber se essa distinção torna possível compreender o estatuto atribuído, numa sociedade como a nossa, aos delinquentes, às minorias étnicas, religiosas, sexuais, aos doentes mentais, aos que estão fora do circuito de produção e consumo" (CHAVES, 2017, p. 227). Diante de todas as nuanças em relação aos deslocamentos da concepção de poder em Foucault, ou mesmo da relação deste com Lévi-Strauss, concentro-me no tema do "desvio". Penso que a menção a Lévi-Strauss, de certa maneira, ratifica alguns traços da relação de oposição entre os empreendimentos reflexivos de Goffman e do próprio Foucault. Ao se afastar de uma concepção de exclusão em Lévi-Strauss, Foucault se distancia também de toda uma tradição psicossociológica incluindo Goffman - que ainda estruturam suas argumentações por meio de noções como "desvio" e "inadaptação". Dirá o próprio Goffman: "Para colocar o quadro de referência resultante no contexto conceptual conveniente será útil considerar o conceito de desvio a partir de diferentes ângulos, constituindo-se este numa ponte que liga o estudo do estigma ao do resto do mundo social." (GOFFMAN, 1978, p.108).

No curso do Collège de France, 1973-1974, Le Pouvoir Psychiatrique, Foucault, afirmando que o poder não pertence nem a alguém nem mesmo a um grupo, pois apenas existiria poder porque há uma dispersão, uma rede, um sistema de diferenças que torna possível o funcionamento desse poder, tenta se afastar dos psicossociólogos da época que veem o asilo como uma instituição senão edificada por regras, uma instituição total entendida em si mesma, na qual o corpo do médico, por exemplo, não teria uma atenção maior do ponto de vista da inscrição e da engrenagem que movimentaria esse poder. Dirá o próprio Foucault (2003, p. 6, tradução nossa):

\footnotetext{
É essa presença física, com aquelas qualidades, que funciona como a cláusula da dissimetria absoluta na ordem regular do asilo. É essa presença que faz com que o asilo não seja como nos diriam os psicossociólogos, uma instituição funcionando segundo regras; é um campo, na realidade, polarizado por uma dissimetria essencial do poder, que toma, então, sua forma, seu rosto, sua inscrição física no corpo mesmo do médico.
}

Antes de tudo, Foucault se preocupa com os processos de racionalização envolvidos na constituição e na gestão do indivíduo no cenário das instituições, permanecendo distante de uma - como apontaria Goffman, - história das instituições. O projeto de Foucault compreende 
menos uma macrofísica da instituição e mais uma microfísica do poder. Lembremos da famosa passagem do acima citado curso Le Pouvoir Psychiatrique: "O que me proponho nesse ano é fazer aparecer a microfísica do poder, antes mesmo de uma análise da instituição." (FOUCAULT, 2003, p. 34, tradução nossa).

\section{CONCLUSÃO}

Se retornarmos - já citado aqui - a 19 de abril de 1983, em Berkeley, Estados Unidos, quando Foucault faz uma das últimas referências a Goffman, encontrar-se-á uma leitura que não se distancia do teor das referências anteriores. "O que chamo de sistema disciplinar é bem mais um tipo de racionalidade que uma instituição total. E é esta a diferença com o que Goffman descreveu, isto é, instituições reais com certo tipo de organização, de organização interna. O que entendo por sistema disciplinar é antes um tipo de racionalidade" (FOUCAULT, 2015, p. 135). O problema, portanto, da disciplina, do poder não é simplesmente institucional, mas passa pelo reconhecimento de um conjunto de dispositivos, de mecanismos, de técnicas presentes de forma capilar em toda uma sociedade. Leitura que já tinha sido ratificada dias antes, 13 de abril, em entrevista com Martin Jay, Leo Lowenthal, Paul Rabinow, Richard Rorty, Charles Taylor, na mesma Univesidade de Berkeley:

\footnotetext{
O poder do tipo disciplinar tal qual aquele que é exercido - que foi exercido ao menos - em certo número de instituições, um pouco no sentido daquilo que Goffman chamava as instituições totais é absolutamente localizado, é uma forma inventada em um momento dado, que produziu certo número de resultados, foi experimentada como totalmente insustentável. (FOUCAULT, 2001, p. 1409, tradução nossa).
}

Ora, é muito comum, ao se falar da trajetória do pensamento de Foucault, acentuaremse os inúmeros deslocamentos - déplacement - encontrados em sua obra. Da Histoire de la Folie em direção às mudanças da análise realizada em Le Pouvoir Psychiatrique, do elogio a etnologia de Lévi-Strauss em Les Mots et les Choses rumo às ressalvas feitas ao antropólogo francês em Les Anormaux. No entanto, desde as primeiras referências no início da década de 1970 até os comentários na década de 1980, a característica fundamental dessa leitura de Foucault sobre as ideias de Goffman é antes de tudo a continuidade. Continuidade de Foucault em uma recusa da distinção entre ações realizadas naquela circunscrição das instituições totais e aquelas ocorridas na sociedade; continuidade em rejeitar uma reflexão acerca do poder que o negativize, que o reduza ao centralismo da autoridade institucional; 
continuidade, portanto, à clara distinção entre esses dois importantes empreendimentos reflexivos do século $\mathrm{XX}$, que até hoje estão presentes nos desafios os quais as ciências humanas não cessam de enfrentar.

\section{REFERÊNCIAS}

CEFÄI, Daniel; GARDELLA, Edouard. Comment analyser une situation selon le dernier Goffman? In: CEFÄI, Daniel; PERREAU, Laurent. ERVING. Goffman et l'ordre de l'interaction. Paris: CURAPP-ESS/CEMS-IMM, 2012.

CHAVES, Ernani. Do mecanismo repressivo à microfisica do poder: Deslocamentos da concepção de Poder em Michel Foucault. In: CHECCHIA, Marcelo (Org.). Combate à vontade de potência. São Paulo: Anna Blume, 2017.

CUSSET, François. French Theory: Foucault, Derrida, Deleuze \& Cie et les mutations de la vie intellectuelle aux États-Unis. Paris: La Découverte, 2003. [Trad. Bras. CUSSET, François. Filosofia Francesa: a influência de Foucault, Derrida, Deleuze \& Cia. Tradução Fátima Murad. Porto Alegre: Editora Artmed, 2008].

DREYFUS, H.; RABINOW, P. Michel Foucault: um parcours philosophique au-delà de l'objectivité et de la subjectivité. Paris: Gallimard, 1984. [Titulo original em inglês: Beyond Structuralisme and Hermaneutics (1982)].

FOUCAULT, Michel. Dits et Écrits II - 1976-1988. Editions Gallimard, 2001.

FOUCAULT, Michel. Histoire de la Sexualité I - La volonté de savoir. Paris:Gallimard, 1976.

FOUCAULT, Michel. Il faut défendre la société . Cours au Collège de France.1976. Paris: Hautes Études/Gallimard-Seuil, 1997.

FOUCAULT, Michel. La Sociéte Punitive. Cours au Collège de France (1972-1973). Paris: Hautes Études/Gallimard-Seuil, 2013.

FOUCAULT, Michel. Les Anormaux. Cours au Collège de France.1974-1975. Paris: Hautes Études/Gallimard-Seuil, 1999.

FOUCAULT, Michel. Le pouvoir psychiatrique-Cours au Collège de France.1973-1974.

Paris: Hautes Études/Gallimard-Seuil, 2003.

FOUCAULT, Michel. Qu'est-ce que la critique? Suivi de La culture de soi. Éditions établie par Henri-Paul Fruchaud et Daniele Lorenzini. Paris: Vrin, 2015.

FOUCAULT, Michel. Surveiller et Punir. Paris:Gallimard, 2010.

FOUCAULT, Michel. Théorias et institutions pénales. Cours au Collège de France (19711972). Paris: Hautes Études/Gallimard-Seuil, 2015.

GOFFMAN, Erving. Manicômios, prisões e conventos. Tradução de Dante Moreira Leite. 7. ed. São Paulo: Perspectiva, 2008.

Sapere aude - Belo Horizonte, v. 8, n. 16, p. 381-394, ago./dez. 2017 - ISSN: 2177-6342 
GOFFMAN, Erving. Estigma. Notas sobre a manipulação da identidade deteriorada. 2. ed. Rio de Janeiro: Zahar Editores, 1978.

GOFFMAN, Erving. A representação do eu na vida cotidiana. Tradução de Maria Célia dos Santos Raposo. 2. ed. Petrópolis, RJ: Vozes, 1983.

HALPERIN, David. Saint Foucault. Trad. Didier Eribon. Paris: Editions EPEL, 2000. [Titulo original em inglês: Saint Foucault- Towards a Gay Hagiography (1995)].

LAVAL, Christian. Ce que Foucault a appris de Bentham. Revue d'études benthamiennes [En ligne], 8, 2011, 01 maio 2011. URL: http://etudes-benthamiennes.revues.org/259Acesso em: 15 jan. 2017.

LEVI-STRAUSS, Claude. Tristes tropiques. Terre Humaine/Poche. Paris: Plon, 2011.

RAVEL, Judith. Le vocabulaire de Foucault. Paris: Ellipses, 2009.

WOHLSEN, Marcus. Foucault at Berkeley. A University transformed, Illuminations. Berkeley's online magazine of research in the arts and humanities, March 2005. Disponível em: 〈www.illuminations.berkeley.edu>. 